Periodica Polytechnica Mechanical Engineering, 65(2), pp. 129-133, 2021

\title{
Thermal Analysis by Finite Elements of Hotends for 3D Printing by Fused Filament Fabrication
}

\author{
Germán Gutiérrez Arias, Fernando Jiménez Díaz, Edwin Rúa Ramirez”, Jorge Valcarcel Guzman¹ \\ 1 Department of Engineering, Faculty of Mechanical Engineering, Santo Tomás University (USTA), CII. 19 No. 11-64, Tunja, \\ P. O. B. 74404 04, Colombia \\ * Corresponding author, e-mail: edwin.rua@usantoto.edu.co
}

Received: 11 April 2020, Accepted: 23 December 2020, Published online: 19 March 2021

\begin{abstract}
Nowadays, 3D printing Fused Filament Fabrication (FFF) currently presents obstacles to achieve high printing speeds, mainly due to the inability of the hotend to process the filament fast enough. This article presents the results of the thermodynamic flow analysis carried out on commercial designs of hotends, in the aim intending to identify the design parameters with a higher incidence in the mass flow of material output, so therefore, in the speed and quality of printing. Finite elements thermal analysis was carried out performed in order to characterize the effect of the materials and geometric design elements of the hotends. In this analysis the behavior of the commercial, the commercial melters' behavior and the effects caused by the changes in geometry and materials were obtained. The control variables were the chamber volume and the glass transition volume of each model. These results will be used as the design criteria of a new hotend.
\end{abstract}

\section{Keywords}

3D printing, extruder, finite elements, hotend, thermal analysis

\section{Introduction}

Among the best known 3D printing techniques is FFF (Manufacture with Molten Filament), which consists of heating a plastic filament, PLA, ABS, or other thermoplastic polymer and extruding it through a nozzle to form, layer by layer, the object to be constructed. Rapid prototyping by FFF has several advantages over other techniques, such as the fact that it is a low-cost $3 \mathrm{D}$ printing technique, easy to build and operate, and prototyping gets done very quickly. 3D printers can be the subject of a complete design since their non-profit origin makes them lack optimization and precision in some aspects [1]. A fundamental element of the printer and determining when it comes to printing quality is the extruder since it takes the filament from the coil, melts it, and deposits it on the printing surface precisely and according to the printing parameters that the printer reads. These consist, independently of the material transport system, of four indispensable components: the filament guide, the hot block, the nozzle, and the heat sink (Fig. 1), which together are known as the hotend.

The nozzle defines the output diameter of the molten material, and therefore the width of each layer in the construction process and its temperature must be constant to ensure a correct flow of the material. This temperature is achieved through the conduction of heat from the hot block, which has an electrical resistance on which the thermal input power to the hotend is controlled. Besides, the hot block incorporates a temperature sensor that allows its monitoring and control. The other upper components of the hotend are designed to reduce heat losses through them [2]. Some extruders incorporate a heat barrier, in a

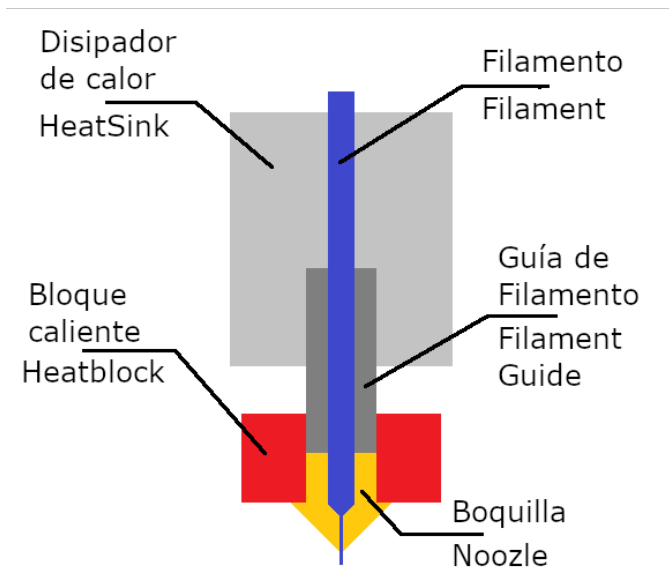

Fig. 1 Parts of a hotend 
material of low thermal conductivity to reduce the flow of the same towards the top. In most designs, at the top of the hotend is an aluminum heat sink and even with forced ventilation through a fan that allows control of the maximum temperature of the hotend.

Temperature control of the hotend is essential to maintain print quality. A strong fluctuation can generate blockages in the hotend, therefore discontinuities in the material flow that affect the quality of the parts manufactured [3]. It is also imperative to reduce heat losses from the hot block to the top of the extruder in order to reduce the power consumption of the heating resistance and to avoid deformations in the plastic parts, usually printed from the extrusion block, which may begin to appear if subjected to temperatures greater than $35^{\circ} \mathrm{C}$ [4].

Thus, the analysis and understanding of the thermal response of the hotend are essential to propose an improvement and optimization of the design of the hotend, which allows improving its performance characteristics: printing speed and operation at higher temperatures, which will allow this manufacturing technique to be used in other applications.

Few studies have tried to analyze the thermal behavior of the hotend and optimize its design. In the revised literature, there are researches [5-7], which have developed finite element analysis models to understand the effect of the geometric parameters of the hotend in mechanical variables of the printing process, such as the pressure drop of the molten material, the material flow and the layer thickness. The results reported by these authors indicate a high relationship between the geometry of the printing nozzle and printing quality. In addition, they indicate that a fundamental component that determines the extruder's thermal behavior is the heat-breaker present in some analyzed designs.

In 2015, Jerez-Mesa and his research team addressed the design of an extruder for Open source 3D printers using finite element analysis to test their thermal performance [1]. In 2016, they found out the influence of the airflow generated by a fan coupled to the extruder on the heat transfer mechanisms during the printing process [8]. Also supported by finite element analysis, this same team carried out a similar work [2] addressed in this article because they carried out the analysis of three extruders, one commercial and two authentic designs. However, in this case, the method of analysis was experimental using thermocouples.

On the other hand, in [9], they focused on how the geometry of the heat sink affects the cooling performance, and in [10] they focused on analyzing the effect of the geometry of the forced ventilation nozzle, on the heat distribution at the hotend. However, both documents limit themselves to identifying the best performing models without clarifying the technical reasons why this occurs.

It is valuable to note that, in the revised documents, when the glass transition temperature $(t g)$ is mentioned, it is in order to characterize some thermoplastic material, but far from being a simple characteristic of the materials, is an element that gives rise to a design criterion that was found to be indispensable, called glass transition volume.

This article presents a finite element analysis of the thermal behavior of three of the most used commercial hotends in low-cost 3D printing, intending to identify the design features with the most significant impact on the quality and speed of printing that will allow proposing an improved own design later on.

The Jerez-Mesa team $[1,2]$ presents a strategy for the development of hotend (liquidizers) based on the generation of design proposals and, subsequently, the comparison of performance with commercial models. In contrast, this article proposes an opposite strategy, in which the design criteria are obtained through an analysis of commercial extruders and contributions made by other in order to establish restrictions, parameters, and variables that will allow in the next stage, the development of a new hotend that will overcome the deficiencies and limitations of the currently available models.

\section{Methodology}

\subsection{Selection of models to be analyzed}

The selection of commercial models of 3D printing hotend $s$ for the realization of thermal simulations was made mainly under the following parameters:

- Compatibility with the most accepted and distributed $3 \mathrm{D}$ printers in the world such as the Prusa i3 and all other printers of the family Reprap, Creality, Anet, Lulzbot, Printbot, Wanhao, Tevo, among others.

- Availability in the local market.

- User reviews on major community websites dedicated to $3 \mathrm{D}$ printing such as all3dp.com [11], matterhackers. com [12], 3dsourced.com [13], and reprap.org [14].

Under these conditions, the following models were selected:

- ED3v6: It is practically the standard model of hotend made entirely of metal in the market. It has a simple design that makes it easy to reproduce, so hundreds of clones are available, making it also economical. In the 
communities, forums and rankings appear in the first places. It is modular, meaning that the heat sink, filament guide, nozzle, and hot block are independent.

- Mk8: Its design has allowed a high acceptance in the last year. It has been replacing the model Ed3v6 in many printers produced massively like the Anet and the Prusa because it consists of only three parts: the filament guide, the hot block, and the nozzle. At the same time, the heat sink is the support of the transport engine, making its manufacture very fast and economical.

- B3 innovations Pico: It has a design that presents a single exterior body (Heat-Block, Heat Sink, and Heater Block) as a single unit piece, made of stainless steel. The Pico design features a cylindrical geometry throughout its body, significantly improving heat distribution throughout it.

\subsection{Digital models}

The hotend was digitally recreated through CAD software; the original designs were modified using the other models' characteristics to clearly identify the influence of these characteristics on the hotend's thermal behavior.

In general, any hotend model follows the same scheme, as shown in Fig. 1. However, they have distinctive features outside the dimensions and materials. The most important being a narrowing of the filament guide diameter just before the hot block, which is known as a heat-breaker. This narrowing decreases the heat conduction to the top of the heatsink hotend [9], mainly for a fully metallic hotend. The benefits and disadvantages caused by this feature will be discussed in the results.

Another distinctive design element is the presence of heat-dissipating fins, usually part of a body independent of the filament guide, but this is fixed in the middle through a thread.

\subsection{Simulation}

Initially, the finite element simulation software was powered by loading the geometries of the components of each model, then the materials corresponding to the parts were assigned, and the meshing process was done, which is to divide the object into a finite number of elements, where the size of each link depends on the desired degree of precision of the simulation, after which the following conditions were assigned:

- Convection with the environment, where the material surrounding each hotend was assigned air at a temperature of $25^{\circ} \mathrm{C}$.
- The thermal load was assigned a nominal power of 40 Watt to an element inserted into the hot block since it is the power that the vast majority of printers can supply, and limiting the maximum temperature to $245^{\circ} \mathrm{C}$ according to Table 1 , corresponding to the maximum melting temperature of the ABS.

Finally, the thermal couplings between components were carried out by contact and by radiation and convection as well, depending on the case. Then, the simulations for each model were executed individually.

The results of simulations; based on the most demanding common material characteristics, ABS, were then verified. All material between the minimum melting temperature and the glass transition temperature is at an undesired temperature because it is in a state that is neither liquid nor solid. This scenario is known as glass transition volume. It is a primary cause of problems at the moment of printing as it prevents the solid filament from acting as a piston to push the molten filament, causing blockages, material recoveries, and the inability to expel high volumes of material by increasing the pressure exerted by the filament propulsion mechanism. Therefore, the calculation of the glass transition volume is one of the fundamental points of this analysis.

From left to right, in Fig. 2, are shown the results of the simulations of the models Ed3v6, Pico, MK8 without heat breaker, and MK8 with heat breaker.

Table 1 Characteristics of 3D printing materials. source: authors

\begin{tabular}{lcccc}
\hline Material & $\begin{array}{c}\text { MFR } \\
\mathrm{g} / 10 \mathrm{~min}\end{array}$ & $\begin{array}{c}\text { UMP } \\
\left({ }^{\circ} \mathrm{C}\right)\end{array}$ & $\begin{array}{c}\text { LMP } \\
\left({ }^{\circ} \mathrm{C}\right)\end{array}$ & $\begin{array}{c}\mathrm{Tg} \\
\left({ }^{\circ} \mathrm{C}\right)\end{array}$ \\
\hline ABS & 4.1 & 245 & 225 & $\sim 97$ \\
PLA & 6.09 & 160 & 145 & $\sim 60$ \\
NYLON & 6.2 & 195 & 185 & $\sim 50$ \\
Flow properties & & MFR & \\
Maximum Temperature of & & $\mathrm{UMP}$ & \\
melting & & & $\mathrm{LMP}$ \\
Minimum temperature of & & $\mathrm{Tg}$ & \\
melting & & & \\
Glass transition temperature & &
\end{tabular}

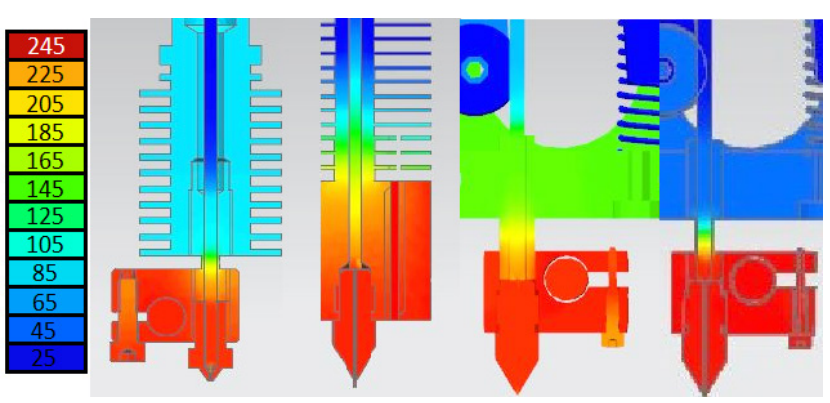

Fig. 2 Result of simulations 


\section{Results}

All tested hotends have a $2 \mathrm{~mm}$ hole for filament passage throughout their full extension to the nozzle, where the diameter is reduced, this continuous $2 \mathrm{~mm}$ diameter hole is a non stipulated standard for almost all FFF hotends. The region of interest is where the filament guide is incorporated or converted into the hot block, so calculating the glass transition volume was simple once having the simulations. It was sufficient to mark the points where the half-filament was $97^{\circ}$ and $225^{\circ}$, respectively, and then measure the distance between these points to calculate the volume of that cylindrical body. The results obtained are shown in Table 2 .

The simulations with the model MK8 (Fig. 3) show the effect of the heat breaker, not only on the filament at the entrance of the hot block but on the dissipating body, where a considerable increase of temperature of this when there is no heat breaker, which results in significant energy losses and in hindering the extrusion process by the anticipated heating of the filament.

\section{Conclusions}

The glass transition volume is a criterion for the design of fuses for 3D printing by molten filament manufacturing since they use the filament as a plunger, generating the need to reduce the glass transition volume.

The heat-breaker already understood as the reduction of thermally conductive material at the heat block entrance translates into better use of energy by reducing the need to dissipate heat.

The use of heat breaker in filament guides has an interesting effect when combined with a heat sink body at the top of them, as it improves the function of the latter in the following way. When there is no heat breaker, the heat sink has to lower the filament temperature that has absorbed heat from the heat block. Instead, when using a heat- breaker, the heat sink body keeps the temperature of the filament at room temperature, and with a forced-air source, can be even below the ambient temperature, significantly improving the piston effect of the solid filament on the cast filament.

Using filament guides with a heat-breaker is indispensable to reduce glass transition volume. Using a stainless
Table 2 Comparison of camera and glass transition volumes.

\begin{tabular}{lccc}
\hline Model & $\begin{array}{c}\text { Chamber } \\
\text { volume } \\
\left(\mathrm{mm}^{3}\right)\end{array}$ & $\begin{array}{c}\text { Glass Transition } \\
\text { Volume with } \\
\text { heat breaker } \\
\left(\mathrm{mm}^{3}\right)\end{array}$ & $\begin{array}{c}\text { Glass Transition } \\
\text { Volume without } \\
\text { heat breaker } \\
\left(\mathrm{mm}^{3}\right)\end{array}$ \\
\hline PICO & 99.67 & N/A & 129.08 \\
ED3v6 & 52.61 & 120,01 & N/A \\
MK8 & 69.8 & 25.2 & 119.4 \\
\hline
\end{tabular}

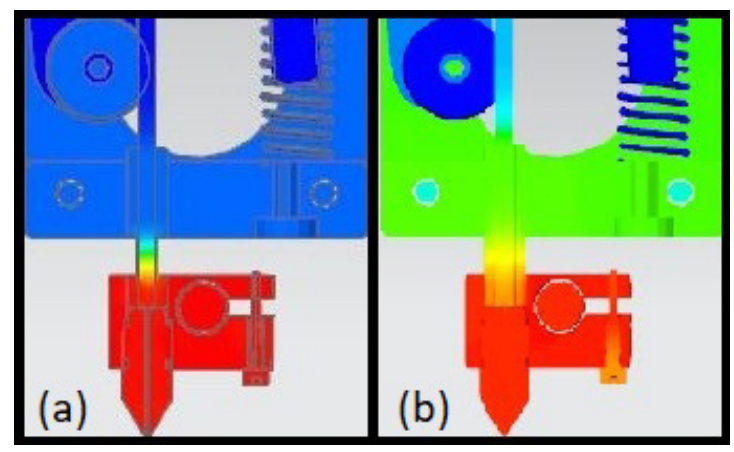

Fig. 3 (a) MK8 with heat breaker; (b) MK8 without heat breaker

steel heat block reduces the internal chamber's use and the heating element's heat.

This study shows the existence of a relation between geometric components of hotends design and its behaviour using our proposal of metrics (glass transition volume).

The study of why this geometrics affects hotends performance is proposed to future works in the aim to develop a new and original hotend design. The current finite element analysis only allows to identify the effects of absence or presence of already identified characteristics, but this comparison don't allow to know the causes. This would be done by the same instrument (finite element analysis) varying the parameters of each feature in order to obtain enough information, then a thermographic study should be used, which allows a correct surface mapping, of temperature even in the presence of high spatial temperature gradients and/or thermal flux [15] to be able to corroborate the data and the conclusions reached theoretically.

\section{Acknowledgement}

The project presented in this article is supported by Santo Tomás University of Colombia. 


\section{References}

[1] Jerez-Mesa, R., Travieso-Rodriguez, J. A., Gomez-Gras, G., Freixedes, J. "Design of Open Source 3D Printer Extruder and Modelling of Thermal Performance with FEA", presented at $19^{\text {th }}$ International Research/Expert Conference "Trends in the Development of Machinery and Associated Technology" (TMT), Barcelona, Spain, Jul. 22-23, 2015. [online] Available at: https://www.researchgate.net/profile/Ja_Travieso-Rodriguez/ publication/284028325_Design_of_open_source_3D_printer_ extruder_and_modelling_of_thermal_performance_with_FEA/ links/564b1ce808ae295f645134e5/Design-of-open-source-3Dprinter-extruder-and-modelling-of-thermal-performance-withFEA.pdf [Accessed: 18 December 2020]

[2] Jerez-Mesa, R., Gomez-Gras, G., Travieso-Rodriguez, J. A., GarciaPlana, V. "A comparative study of the thermal behavior of three different 3D printer liquefiers", Mechatronics, 56, pp. 297-305, 2018. https://doi.org/10.1016/j.mechatronics.2017.06.008

[3] Turner, B. N., Strong, R., Gold, S. A. "A review of melt extrusion additive manufacturing processes: I. Process design and modeling", Rapid Prototyping Journal, 20(3), pp. 192-204. 2014.

https://doi.org/10.1108/RPJ-01-2013-0012

[4] Domingo-Espin, M., Borros, S., Agullo, N., Garcia-Granada, A. A., Reyes, G. "Influence of Building Parameters on the Dynamic Mechanical Properties of Polycarbonate Fused Deposition Modeling Parts", 3D Printing and Additive Manufacturing, 1(2), pp. $70-77,2014$.

https://doi.org/10.1089/3dp.2013.0007

[5] Sukindar, N. A., Ariffin, M. K. A., Baharudin, B. T. H. T., Jaafar, C. N. A., Ismail, M. I. S. "Analyzing the Effect of Nozzle Diameter in Fused Deposition Modeling for Extruding Polylactic Acid Using Open Source 3D Printing", Jurnal Teknologi, 78(10), pp. 7-15, 2016.

https://doi.org/10.11113/jt.v78.6265

[6] Papon, M. E. Arafat., Haque, A., Sharif, M. A. R. "Effect of Nozzle Geometry on Melt Flow Simulation and Structural Property of Thermoplastic Nanocomposites in Fused Deposition Modeling", presented at Thirty-second Technical Conference, West Lafayette, IN, USA, Oct. 23, 2017.

https://doi.org/10.12783/asc2017/15339

[7] Sukindar, N. A., Ariffin, M. K. A. M., bin Baharudin, B. T. H. T., Jaafar, C. N. A., Ismail, M. I. S. "Comparison on Dimensional Accuracy Using a Newly Developed Nozzle for Open-Source 3D Printer", Applied Mechanics and Materials, 859, pp. 15-19, 2016. https://doi.org/10.4028/www.scientific.net/amm.859.15

[8] Jerez-Mesa, R., Travieso-Rodriguez, J. A., Corbella, X., Busqué, R., Gomez-Gras, G. "Finite element analysis of the thermal behavior of a RepRap 3D printer liquefier", Mechatronics, 36, pp. 119-126, 2016.

https://doi.org/10.1016/j.mechatronics.2016.04.007
[9] Günel, O., Koc, E., Tiryaki, G. "Investigation of Heat Sink Geometry Effect on Cooling Performance for a FDM 3D Printer Liquefier", In: International Conference on Energy and Thermal Engineering, Istanbul, Turkey, 2017, pp. 569-573. [online] Available at: https://www.researchgate.net/profile/ Onur_Guenel/publication/318038275_INVESTIGATION_ OF_HEAT_SINK_GEOMETRY_EFFECT_ON_COOLING_ PERFORMANCE_FOR_A_FDM_3D_PRINTER_LIQUEFIER/ links/5a 9ebe4345851543e6341e06/INVESTIGATIONOF-HEAT-SINK-GEOMETRY-EFFECT-ON-COOLINGPERFORMANCE-FOR-A-FDM-3D-PRINTER-LIQUEFIER.pdf [Accessed: 18 December 2020]

[10] Günel, O., Koc, E., Yavuz, T. "Investigation of Thermal Effect on 3D Printer Liquefier of different Cooling Fan Nozzle Geometry", In: International Conference on Energy and Thermal Engineering, Istanbul, Turkey, 2017, pp. 418-422. [online] Available at: https://www.researchgate.net/profile/ Onur_Guenel/publication/318038107_INVESTIGATION_OF_ THERMAL_EFFECT_ON_3D_PRINTER_LIQUEFIER_ OF_DIFFERENT_COOLING_FAN_NOZZLE_GEOMETRY/ links/5a9ebdc6a6fdcc22e2cb33d6/INVESTIGATION-OFTHERMAL-EFFECT-ON-3D-PRINTER-LIQUEFIER-OFDIFFERENT-COOLING-FAN-NOZZLE-GEOMETRY.pdf [Accessed: 18 December 2020]

[11] All3DP "Best 3D Printer Extruder Hot Ends", [online] Available at: https://m.all3dp.com/1/best-3d-printer-hot-ends/ [Accessed: 14 May 2020]

[12] MatterHackers "HotEnds", [online] Available at: https://www. matterhackers.com/store/c/HotEnds [Accessed: 14 May 2020]

[13] 3D Sourced "The Best 3D Printer Hot Ends Buyer's Guide", [online] Available at: https://www.3dsourced.com/guides/best-3dprinter-hot-end/ [Accessed: 14 May 2020]

[14] RepRap "Hot End Comparison", [online] Available at: https://reprap. org/wiki/Hot_End_Comparison [Accessed: 14 May 2020]

[15] Muñoz-Potosi, A., Pencue-Fierro, L., León-Téllez, J. "Análisis Termográfico Para La Determinación De Puntos Críticos En Equipos Mecánicos Y Eléctricos" (Thermographic Analysis for the Determination of Critical Points in Mechanical and Electrical Equipment), Bistua: Revista de la Facultad de Ciencias Básicas, 7(1), pp. 1-4. 2009. [online] Available at: https://www.redalyc. org/pdf/903/90312171013.pdf [Accessed: 18 December 2020] (in Spanish) 